\title{
Expression and Effects of Ligand-activated Estrogen Receptors in Chronic Lymphocytic Leukemia
}

\author{
MOHAMMAD SHARIF HASNI ${ }^{1}$ and KONSTANTIN YAKIMCHUK ${ }^{2}$ \\ ${ }^{1}$ Institute of Biochemistry, University of Balochistan, Quetta, Pakistan; \\ ${ }^{2}$ Department of Biosciences and Nutrition, Neo, Karolinska Institute, Stockholm, Sweden
}

\begin{abstract}
Background/Aim: Recent epidemiological data indicate that lymphoid tumors may be influenced by estrogens. The effects of estrogens are mediated via nuclear estrogen receptors $\alpha(E R \alpha)$ and $\beta(E R \beta)$. This study investigated the potential functions of ligand-activated ERs in chronic lymphocytic leukemia (CLL). Materials and Methods: The ER mRNA expression in B lymphocytes isolated from patients with CLL was analyzed by quantitative real-time polymerase chain reaction. To evaluate the effects of ER $\beta$ signaling, primary CLL cells and CLL-derived MEC1 cells were treated with selective ER $\beta$ agonists. Results: The $m R N A$ expression of $E R \alpha, E R \beta 1$ and its splice variant $E R \beta 2$ was detected in CLL cells. Selective ER $\beta$ agonist 2,3-bis(4hydroxy-phenyl)-propionitrile induced apoptosis in primary CLL cells and suppressed the growth of CLL-derived MEC1 cells. Conclusion: A suppressive effect of ER $\beta$ agonists on the growth of ERß-expressing CLL cells was found, indicating that ER $\beta$ may be considered as a potential therapeutic target in CLL.
\end{abstract}

Hematological malignancies are not traditionally considered to be hormone regulated. Nevertheless, recently accumulated epidemiological data suggest that many lymphoid tumors are likely to be under the influence of estrogen due to the lower incidence and better prognosis of hematological cancer in males (1-4). Amongst B-cell lymphomas, the highest male/female ratio was reported for Burkitt's lymphoma and mantle cell lymphoma $(2,5)$. Regarding leukemia, male patients were reported to have a two-fold higher incidence of both acute $(2,4)$ and chronic lymphocytic leukemia (CLL) (6) than females. Furthermore, female patients with CLL

Correspondence to: Konstantin Yakimchuk, MD, Ph.D., Karolinska Institute, Department of Biosciences and Nutrition, Novum, SE14183 Huddinge, Sweden. Tel: +46 8609254, Fax: +46 852481135, e-mail: konstantin.yakimchuk@ki.se

Key Words: Chronic lymphocytic leukemia, estrogen receptors, apoptosis, B-cells. were found to have better overall 10-year survival and a more benign clinical course than male patients (7).

The effects of estrogens are primarily mediated via nuclear estrogen receptors $\alpha(E R \alpha)$ and $\beta$ (ER $\beta)$ (8). Significant differences in transcriptional responses between $\mathrm{ER} \alpha$ and $\mathrm{ER} \beta$ were demonstrated in vivo (9). With regard to cell growth, ligand-dependent activation of ER $\alpha$ and ER $\beta$ leads to opposite effects, since estrogens promote proliferation via $\mathrm{ER} \alpha(10,11)$, but suppress proliferation and stimulate differentiation in different cell types via ER $\beta$ (12, 13). Furthermore, analysis of cells expressing both ERs and treated with $E R \alpha$ - or $E R \beta$-selective agonists or estradiol $\left(E_{2}\right)$ showed that the cellular responses were distinct for each type of ligand (14). These findings suggest that ERs regulate both common and ER subtype-specific genes. With regard to the immune system, ER $\beta$ was found to be the dominant ER expressed in mature leukocytes from peripheral blood, tonsils or spleen of healthy individuals (15). The potential importance of ER $\beta$ signaling in B cells was earlier demonstrated in $\mathrm{Erb}^{-/-}$mice, which developed chronic leukemia with lymphoid blast crisis (16).

Our earlier data suggested the potential effects of $E_{2}$ on lymphoma growth by demonstrating faster growth of engrafted mouse lymphoma cells in male than in female mice (17). Moreover, our earlier studies found expression of the ERs in lymphoma cell lines and tissues from patients with different lymphomas and showed that the growth of human mantle cell lymphoma, Burkitt's lymphoma and diffuse large B-cell lymphoma was strongly suppressed by selective ER $\beta$ agonists in mice grafted with lymphoma cells $(18,19)$.

With regard to leukemia, our earlier study reported for the first time the expression of ERs in peripheral blood mononuclear cells (PBMCs) from patients with CLL by immunocytochemistry (20). However, the detailed analysis of the expression and activity of ERs in B-lymphocytes in leukemia is needed in order to understand their potential functions in CLL. Furthermore, due to notable specificity limitations of many existing antibodies to $\operatorname{ER} \beta$ (21), the characterization of ER mRNA expression remains highly important. 
This study aimed to analyze the mRNA expression of nuclear ERs in primary CLL cells. In addition, we studied the potential effects of selective ER $\alpha$ and ER $\beta$ agonists on the growth of CLL cells in culture.

\section{Materials and Methods}

Description of patients with CLL included in the study. Twelve patients (10 males and two females) were included in the study after obtaining an informed consent. The patients were diagnosed according to the current CLL diagnostic guidelines (22). The median age at the time of blood sampling was 71 years. Five patients had progressive disease at sampling, while 22 were in a stable phase. Six patients had progressive disease (Rai stages III and IV) at the sampling time, four patients had Rai stage II disease and two had Rai stage I disease (Table I). The study was approved by the local Ethical Board at Karolinska Institute, Stockholm (no. 99-154). This research was conducted in accordance with the Declaration of Helsinki.

Cell isolation and preparation. PBMCs were isolated from heparinized blood samples Ficoll-Hypaque density gradient centrifugation (Pharmacia Biotech, Uppsala, Sweden). CD19+ Blymphocytes were isolated from PBMCs by labeling cells $\left(2 \times 10^{5}\right.$ per sample) with anti-CD19-fluorescein isothiocyanate (FITC) (Invitrogen, Carlsbad, CA, USA) followed by flow cytometric sorting with FACSVantage/DiVa (Becton Dickinson, San Jose, CA, USA). The purity of CD $19^{+}$cells was $95 \%$. All cell sorting was carried out using freshly isolated PBMCs.

Cell culture and synthetic compounds. Human cell line MEC1 originally established from the spontaneous outgrowth of explanted CLL cells (23) was maintained in RPMI 1640 medium supplemented with $10 \%$ fetal bovine serum, $2 \mathrm{mM}$ L-glutamine, 100 IU of penicillin per $\mathrm{ml}$ and $100 \mu \mathrm{g} / \mathrm{ml}$ of streptomycin at $37^{\circ} \mathrm{C}$ in $5 \%$ $\mathrm{CO}_{2}$. RPMI 1640 medium was purchased from HyClone (Logan, UT, USA). $E_{2}$, selective ER $\beta$ agonist 2,3-bis(4-hydroxy-phenyl)propionitrile (DPN), selective ER $\alpha$ agonist 4,4',4"'-(4-propyl-[1H]pyrazole-1,3,5-triyl)trisphenol (PPT) and dimethyl sulfoxide (DMSO) were obtained from Sigma-Aldrich (St Louis, MO, USA). A selective ER $\beta$ agonist KB9520 (17) was provided by Karo Bio AB (Huddinge, Sweden). An ER antagonist ICI 182.780 was obtained from Tocris Bioscience (Ellisville, MO, USA).

Quantitative real-time polymerase chain reaction ( $R T-q P C R)$. For RTqPCR analysis, $\mathrm{CD} 19^{+} \mathrm{B}$-cells isolated from peripheral blood of patients with CLL were subjected to RNA isolation. Total RNA was obtained using the RNeasy kit (Qiagen, Valencia, CA, USA) according to the manufacturer's instructions. The concentration of isolated RNA was determined by a NanoDrop ND-1000 UV Spectrophotometer (NanoDrop Technologies, Wilmington, DE, USA). Synthesis of cDNA and quantitative real-time PCR for detecting the expression of ER $\alpha$, $E R \beta 1$ and ER $\beta 2$ mRNAs were performed as described earlier (24). For RT-qPCR, the following specific forward and reverse primers were used: Ribosomal protein lateral stalk subunit P0 (RPLPO; reference gene) forward: GTGTTCGACAATGGCAGCAT, reverse: GACACCC TCCAGGAAGCGA; ESR1: forward: GCTACGAAGTGGGAATG ATGAAAG, reverse: TCTGGCGCTTGTGTTTCAAC; ESR2 (wildtype ER $\beta 1$ ): forward: TGCGGAACCTCAAAA GAGTC, reverse:
Table I. Clinical characteristics of patients with chronic lymphocytic leukemia.

\begin{tabular}{lccc}
\hline Patient no. & Gender & Age, years & Rai stage \\
\hline 1 & M & 73 & I \\
2 & M & 63 & I \\
3 & F & 77 & II \\
4 & M & 86 & II \\
5 & M & 65 & II \\
6 & M & 62 & II \\
7 & F & 69 & III \\
8 & M & 81 & III \\
9 & M & 54 & III \\
10 & M & 84 & III \\
11 & M & 67 & III \\
12 & M & 72 & IV \\
\hline
\end{tabular}

F: Female, M: male.

CATCCCTCTTTGAACCTGGA; ESR2 (splice variant ER $\beta 2$ ): forward: TCCATGCGCCTGGCTAAC, reverse: CCATCGTTGC TTCAGGCAA. The specificity of PCR results was evaluated by dissociation curves, and for the calculation of the corresponding results the $2^{-\Delta \Delta \mathrm{CT}}$ method was applied. The amount of each transcript was normalized to the reference gene $R P L P O$ and presented as relative mRNA expression levels.

Treatments in vitro. Primary CLL cells and MEC1 cells were treated

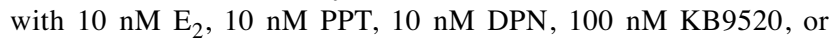
vehicle (DMSO) for up to $96 \mathrm{~h}$ in phenol red-free culture medium supplemented with $10 \%$ charcoal-purified fetal bovine serum and $1 \% \mathrm{~L}$-glutamine at $37^{\circ} \mathrm{C}$ in $5 \% \mathrm{CO}_{2}$. The final DMSO concentration was $<0.001 \%$ in all cell culture experiments. Cell proliferation was estimated by a Bürker cell counter. Cell viability was evaluated using Trypan blue.

Terminal deoxynucleotidyl transferase dUTP nick end labeling (TUNEL) assay. For TUNEL assay, CLL cells were treated with the selective ER $\beta$ agonist DPN, ER antagonist ICI 182.780, a combination of DPN with ICI 182.780 or vehicle. Following the treatment, $1 \times 10^{5}$ CLL cells from each treatment condition were plated on glass slides using cytospin cytocentrifuge (Thermo Fisher Scientific, Waltham, MA, USA) at $57 \times g$ for $15 \mathrm{~min}$. Prior to the assay, the cells were fixed with $4 \%$ paraformaldehyde (Merck, Whitehouse Station, NJ, USA) for $10 \mathrm{~min}$ at $4^{\circ} \mathrm{C}$ and permeabilized with $0.5 \% \mathrm{NP}-40$ for $10 \mathrm{~min}$ at room temperature. Blocking was performed using $1 \%$ bovine serum albumin (Sigma-Aldrich, St. Louis, MO, USA) in phosphate buffered saline for $1 \mathrm{~h}$ at $4^{\circ} \mathrm{C}$. The TdT-mediated dUTP nick-end labeling (TUNEL) assay was performed according to the manufacturer's protocol (Roche Diagnostics, Risch-Rotkreuz, Switzerland). Briefly, 50 $\mu$ l of the TUNEL reaction mixture was applied to each slide, followed by 60 min incubation at $37^{\circ} \mathrm{C}$ in a humidity chamber protected from light. For nuclear staining, 4',6-diamidino-2-phenylindole (Sigma-Aldrich) was applied. The slides were mounted using fluorescence mounting medium (Dako, Santa Clara, CA, USA). Imaging was performed by a Zeiss Axioplan2 immunofluorescence microscope with filters for specific detection of tetramethylrhodamine (red) and 4',6-diamidino- 


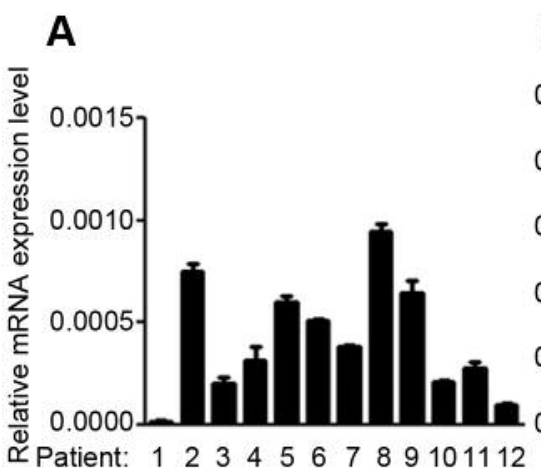

ESR1
B

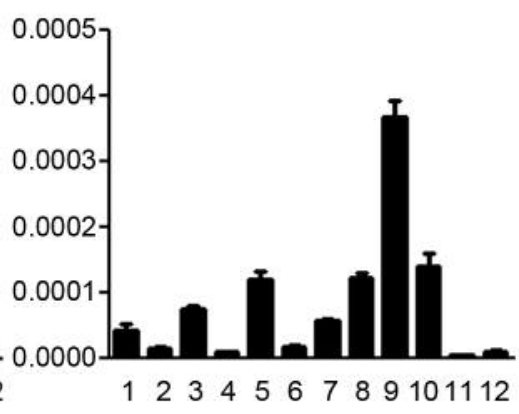

ESR2 (wild-type ERß1)
C

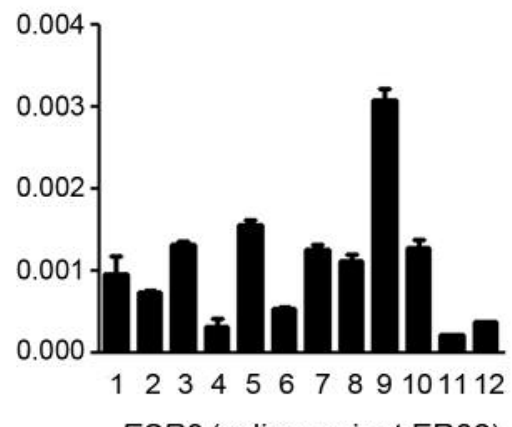

ESR2 (splice variant ERß2)

Figure 1. Expression of estrogen receptor $\alpha(E S R 1)(A)$, estrogen receptor $\beta$ (ESR2; wild-type ER $\beta 1)(B)$ and ESR2 (splice variant ER $\beta 2)(C)$ in patients with chronic lymphocytic leukemia (CLL) The mRNA expression in primary CD19+ ${ }^{+}$LL cells was measured by quantitative real-time polymerase chain reaction.

2-phenylindole (blue). Quantification of the TUNEL assay was performed by counting the number of positively stained cells in four randomly chosen nonoverlapping fields from each slide.

Statistical analysis. Unpaired Student $t$-test was applied for the statistical analysis. Mean values \pm standard deviations are presented. $p$-Values of 0.05 or less were considered significant.

\section{Results}

Expression of ERs in B-cells isolated from patients with CLL. High mRNA expression of all three ERs was detected in all patients with CLL (Figure 1). Potential correlation of mRNA ER expression with Rai stages was analyzed in the group of patients with CLL with intermediate risk (Rai stages I and II) and in the group with high risk (Rai stages III and IV). No significant correlation of $\mathrm{ER} \alpha$ and ER $\beta 1 \mathrm{mRNA}$ and clinical data was found. In contrast, with regard to ER $\beta 2$ expression, there was a tendency for lower ER $\beta 2$ mRNA expression in samples from patients with CLL with intermediate risk $(0.00078$ versus 0.00123 in high-risk CLL) (Figure 1). However, the difference was not statistically significant $(p=0.255)$. As expected, a similar correlation with ER $\beta 2$ mRNA expression was observed for absolute lymphocyte count, with a mean of 97 in the intermediate-risk and 204 in the high-risk group.

A selective ER $\beta$ agonist activates apoptosis in primary CLL cells in vitro. To analyze the potential actions of ligandactivated ER $\beta$ in leukemia cells, primary CD $19^{+}$cells isolated from PBMCs of three patients with CLL were treated with a selective ER $\beta$ agonist DPN. Primary ER $\beta$ expressing CLL cells were treated in culture with ER $\beta$ agonist DPN, or a combination of DPN and ER inhibitor ICI 182.780, or vehicle for $48 \mathrm{~h}$. The effects of the treatments on apoptosis were evaluated by TUNEL assay.

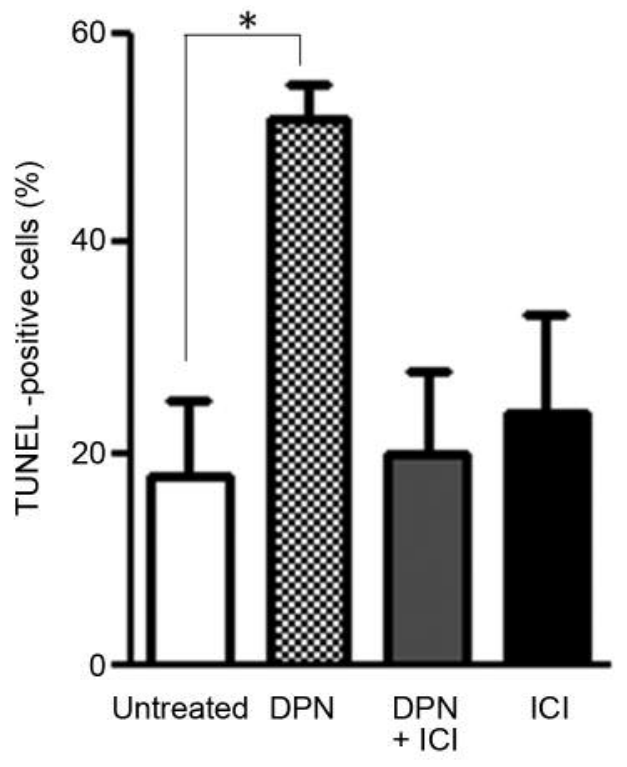

Figure 2. Treatment with a selective estrogen receptor $\beta$ (ER $\beta)$ agonist 2,3-bis(4-hydroxy-phenyl)-propionitrile (DPN) stimulates apoptosis in primary human chronic lymphocytic leukemia (CLL) cells via ER $\beta$. Terminal deoxynucleotidyl transferase dUTP nick end labeling (TUNEL) assay showed a significant increase of apoptosis in CLL cells treated with $1 \mu M D P N$ in comparison to vehicle-treated cells. The induction of apoptosis by DPN was inhibited by co-treatment with ER antagonist $1 \mu$ M ICI 182.780 (ICI). The results of the TUNEL assay are presented as the percentage of TUNEL-positive cells evaluated at $\times 200$ magnification. Data are representative of three independent experiments. *Significantly different at $p<0.05$.

We found that apoptosis was significantly activated by DPN treatment compared to the vehicle treatment (Figure 2). Co-treatment with ICI 182.780 significantly suppressed pro-apoptotic effects of DPN treatment, suggesting that the 

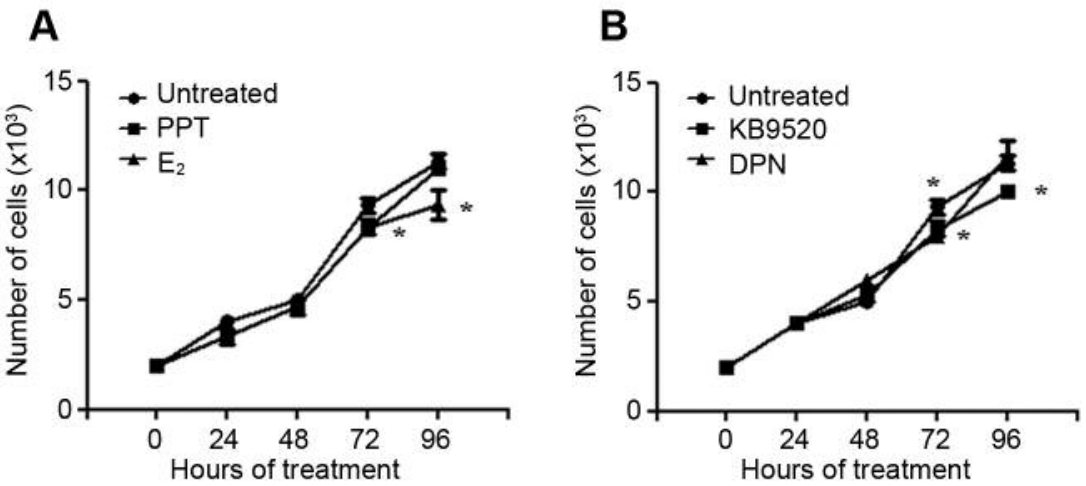

Figure 3. The selective estrogen receptor (ER) $\beta$ agonists 2,3-bis(4-hydroxy-phenyl)-propionitrile (DPN) and KB9520 suppress the growth of MEC1 human chronic lymphocytic leukemia (CLL) cells in vitro. MEC1 cells were treated in culture with vehicle (untreated), $10 \mathrm{nM}$ of selective ER $\alpha$ agonist 4,4',4"-(4-propyl-[1H]-pyrazole-1,3,5-triyl)trisphenol (PPT), 10 nM estradiol (E $\left.E_{2}\right)(A), 100$ nM of a selective ER $\beta$ agonist KB9520 or $10 \mathrm{nM}$ of selective ERß agonist DPN (B) for 24, 48, 76 or $94 \mathrm{~h}$. Cell numbers were recorded at every time point. Data are representative of two independent experiments. *Significantly different at $p<0.05$ vs. untreated.

induction of apoptosis in CLL cells in vitro may be mediated via $\mathrm{ER} \beta$, since DPN is considered to be a selective ER $\beta$ agonist.

Suppressive effects of selective ER $\beta$ agonists on CLL cell growth. To study the inhibitory effects of ER $\beta$ agonists, MEC1 cells were treated with either the selective ER $\beta$ agonist DPN or vehicle. MEC1 growth was significant suppressed by $E_{2}$ and selective ER $\beta$ agonist KB9520 in comparison to vehicle (Figure 3 ). The effect was significant at all the experimental time points. In addition, another selective ER $\beta$ agonist DPN also had a suppressive effect on the growth of MEC1 cells, with significant inhibition at 48 $\mathrm{h}$ of treatment and a suppressive tendency at other experimental time points. In contrast to the ER $\beta$ agonists, treatment with selective ER $\alpha$ agonist PPT did not have any effect on leukemia cells (Figure 3).

\section{Discussion}

In this study, we analyzed the mRNA expression of the ERs in B-lymphocytes from patients with CLL. The results showed high mRNA expression of both main nuclear ERs and an ER $\beta$ splice variant ER $\beta 2$ in CLL cells. As far as we are aware, this is the first study evaluating the mRNA expression of nuclear ERs in B-cells from patients with CLL. The present findings are in line with our earlier data showing high expression of ER $\beta 1$ and ER $\beta 2$ in total PBMCs from patients with CLL (20). Moreover, in the present study we found relatively high expression of $\mathrm{ER} \alpha$ mRNA in all patients with CLL.

Expression of ER $\beta 2$ was previously found in breast tumor tissues and was associated with a weak response to tamoxifen (25). However, another study showed significantly better clinical outcome in a subset of patients with breast tumor tissues with high expression of ER $\beta 2$ (26). An earlier study demonstrated that ER $\beta 2$ may inhibit ER $\alpha$-mediated transactivation through estrogen-responsive elements in breast cancer cells in culture (27). With regard to the expression of ER $\beta$ splice variants in the immune system, ER $\beta 2$ protein expression was found in normal immune tissues, such as thymus and peripheral blood leukocytes $(28,29)$. Earlier study of ER $\beta 2$ in breast cancer tissue showed a low correlation of mRNA and protein levels of ER $\beta 2$ (26). However, in line with our previous study, which showed increased expression of ER $\beta 2$ in total PBMCs obtained from patients with CLL (20), we detected high expression of ER $\beta 2$ mRNA in all CD $19^{+}$CLL samples.

Ligand-independent activation of apoptosis by $\operatorname{ER} \beta$ expression was initially shown in ovarian and prostate malignant cells in vitro $(30,31)$. Our earlier study demonstrated induction of apoptosis in lymphomas by selective ER $\beta$ agonists using immunodeficient mice engrafted with lymphoma cells (17). In addition, ligandmediated activation of ER $\beta$ was recently reported to induce autophagy in lymphoma cells (32). Furthermore, raloxifene, a selective ER modulator with binding affinity for both ER $\alpha$ and ER $\beta$, was shown to induce apoptosis in acute lymphoblastic leukemia cells (33). In the present study, treatment with DPN induced apoptosis in primary CLL cells in vitro. Furthermore, since DPN is considered to be a selective $\operatorname{ER} \beta$ agonist, clear inhibition of pro-apoptotic effects of DPN by co-administration with ER inhibitor ICI 182.780 indicates that the induction of apoptosis in CLL cells in vitro may be mediated via $\mathrm{ER} \beta$, since DPN is considered to be a selective ER $\beta$ agonist. 
The results of the treatment of MEC1 CLL cells with ER agonists and $E_{2}$ showed the suppressive effects of both $E_{2}$ and a selective ER $\beta$ agonist on the growth of CLL cells, suggesting that this growth inhibition is mediated via ligand-activated ER $\beta$. The suppressive effects of $E_{2}$ are in parallel with our earlier results showing inhibition of lymphoma cell growth by $\mathrm{E}_{2}$ in vitro (17). This indicates the potential influence of $\mathrm{E}_{2}$ on CLL cells. Although DPN, an ER $\beta$ agonist, only had a tendency to inhibit leukemia cell growth, KB9520 significantly suppressed the growth of MEC1 cells. The observed differences may be related to the higher ER $\beta$ binding selectivity of KB9520 in comparison to DPN. Moreover, higher doses of DPN may be needed to have a significant suppression of leukemia cell growth. In contrast to the ER $\beta$ ligands, the selective ER $\alpha$ agonist PPT did not affect the growth of MEC1 cells. This observation indicates that ligand-activated ER $\alpha$ does not influence the growth of leukemia cells and is in consonance with our earlier studies demonstrating no effect of PPT on lymphoma growth both in vitro and in vivo $(17,18)$.

Our data demonstrated the expression of nuclear ERs in B-cells in CLL at the mRNA level and suggest that selective $\operatorname{ER} \beta$ agonists may influence growth and induce apoptosis of these cells via ER $\beta 1$. Additional studies of the suppressive and pro-apoptotic effects of selective ER $\beta$ agonists on leukemia cells are required to further explore $\operatorname{ER} \beta$ as a novel potential therapeutic target in CLL.

\section{Conflicts of Interest}

The Authors declare no conflicts of interest in regard to this study.

\section{Acknowledgements}

This work was supported by the Grants from the Swedish Cancer Society (CAN2014/593 and CAN2017/404).

\section{References}

1 Parkin DM, Stiller CA, Draper GJ and Bieber CA: The international incidence of childhood cancer. Int J Cancer 42(4): 511-520, 1988.

2 Morton LM, Wang SS, Devesa SS, Hartge P, Weisenburger DD and Linet MS: Lymphoma incidence patterns by WHO subtype in the United States, 1992-2001. Blood 107(1): 265-276, 2006.

3 Dorak MT and Karpuzoglu E: Gender differences in cancer susceptibility: An inadequately addressed issue. Front Genet 3: 268, 2012.

4 Forsythe A, Breland T, Majumdar S, Elkin TD, Johnson D and Megason G: Gender differences in incidence rates of childhood B-precursor acute lymphocytic leukemia in mississippi. J Pediatr Oncol Nurs 27(3): 164-167, 2010.

5 Leux C, Maynadie M, Troussard X, Cabrera Q, Herry A, Le Guyader-Peyrou S, Le Gouill S and Monnereau A: Mantle cell lymphoma epidemiology: A population-based study in France. Ann Hematol 93(8): 1327-1333, 2014.
6 Catovsky D, Fooks J and Richards S: Prognostic factors in chronic lymphocytic leukaemia: The importance of age, sex and response to treatment in survival. A report from the MRC CLL 1 trial. MRC Working Party on Leukaemia in Adults. Br J Haematol 72(2): 141-149, 1989.

7 Catovsky D, Wade R and Else M: The clinical significance of patients' sex in chronic lymphocytic leukemia. Haematologica 99(6): 1088-1094, 2014.

8 Heldring N, Pike A, Andersson S, Matthews J, Cheng G, Hartman J, Tujague M, Strom A, Treuter E, Warner M and Gustafsson JA: Estrogen receptors: How do they signal and what are their targets. Physiol Rev 87(3): 905-931, 2007.

9 Fox EM, Davis RJ and Shupnik MA: Erbeta in breast cancer-Onlooker, passive player, or active protector? Steroids 73(11): 1039-1051, 2008.

10 Cheng G, Weihua Z, Warner M and Gustafsson JA: Estrogen receptors ER alpha and ER beta in proliferation in the rodent mammary gland. Proc Natl Acad Sci USA 101(11): 3739-3746, 2004.

11 Omoto Y, Imamov O, Warner M and Gustafsson JA: Estrogen receptor alpha and imprinting of the neonatal mouse ventral prostate by estrogen. Proc Natl Acad Sci USA 102(5): 14841489, 2005.

12 Warner M and Gustafsson JA: The role of estrogen receptor beta (erbeta) in malignant diseases - a new potential target for antiproliferative drugs in prevention and treatment of cancer. Biochem Biophys Res Commun 396(1): 63-66, 2010.

13 Strom A, Hartman J, Foster JS, Kietz S, Wimalasena J and Gustafsson JA: Estrogen receptor beta inhibits 17beta-estradiolstimulated proliferation of the breast cancer cell line T47D. Proc Natl Acad Sci USA 101(6): 1566-1571, 2004.

14 Helguero LA, Faulds MH, Gustafsson JA and Haldosen LA: Estrogen receptors alfa (ERalpha) and beta (ERbeta) differentially regulate proliferation and apoptosis of the normal murine mammary epithelial cell line HC11. Oncogene 24(44): 6605-6616, 2005.

15 Shim GJ, Gherman D, Kim HJ, Omoto Y, Iwase H, Bouton D, Kis LL, Andersson CT, Warner $M$ and Gustafsson JA: Differential expression of oestrogen receptors in human secondary lymphoid tissues. J Pathol 208(3): 408-414, 2006.

16 Shim GJ, Wang L, Andersson S, Nagy N, Kis LL, Zhang Q, Makela S, Warner $M$ and Gustafsson JA: Disruption of the estrogen receptor beta gene in mice causes myeloproliferative disease resembling chronic myeloid leukemia with lymphoid blast crisis. Proc Natl Acad Sci USA 100(11): 6694-6699, 2003.

17 Yakimchuk K, Iravani M, Hasni MS, Rhonnstad P, Nilsson S, Jondal $\mathrm{M}$ and Okret $\mathrm{S}$ : Effect of ligand-activated estrogen receptor beta on lymphoma growth in vitro and in vivo. Leukemia 25(7): 1103-1110, 2011.

18 Yakimchuk K, Hasni MS, Guan J, Chao MP, Sander B and Okret S: Inhibition of lymphoma vascularization and dissemination by estrogen receptor beta agonists. Blood 123(13): 2054-2061, 2014.

19 Hasni MS, Berglund M, Yakimchuk K, Guan J, Linderoth J, Amini RM, Enblad G and Okret S: Estrogen receptor beta1 in diffuse large B-cell lymphoma growth and as a prognostic biomarker. Leuk Lymphoma 58(2): 418-427, 2017.

20 Yakimchuk K, Norin S, Kimby E, Hagglund H, Warner M and Gustafsson JA: Up-regulated estrogen receptor beta2 in chronic lymphocytic leukemia. Leuk Lymphoma 53(1): 139-144, 2012. 
21 Nelson AW, Groen AJ, Miller JL, Warren AY, Holmes KA, Tarulli GA, Tilley WD, Katzenellenbogen BS, Hawse JR, Gnanapragasam VJ and Carroll JS: Comprehensive assessment of estrogen receptor beta antibodies in cancer cell line models and tissue reveals critical limitations in reagent specificity. Mol Cell Endocrinol 440: 138-150, 2017.

22 Hallek M, Cheson BD, Catovsky D, Caligaris-Cappio F, Dighiero G, Dohner H, Hillmen P, Keating MJ, Montserrat E, Rai KR, Kipps TJ and International Workshop on Chronic Lymphocytic L: Guidelines for the diagnosis and treatment of chronic lymphocytic leukemia: A report from the International Workshop on Chronic Lymphocytic Leukemia updating the National Cancer Institute-Working Group 1996 guidelines. Blood 111(12): 5446-5456, 2008.

23 Stacchini A, Aragno M, Vallario A, Alfarano A, Circosta P, Gottardi D, Faldella A, Rege-Cambrin G, Thunberg U, Nilsson $\mathrm{K}$ and Caligaris-Cappio F: MEC1 and MEC2: Two new cell lines derived from B-chronic lymphocytic leukaemia in prolymphocytoid transformation. Leuk Res 23(2): 127-136, 1999.

24 Qiao S, Chen L, Okret S and Jondal M: Age-related synthesis of glucocorticoids in thymocytes. Exp Cell Res 314(16): 30273035, 2008.

25 Saji S, Omoto Y, Shimizu C, Warner M, Hayashi Y, Horiguchi S, Watanabe T, Hayashi S, Gustafsson JA and Toi M: Expression of estrogen receptor (ER) (beta)CX protein in ER(alpha)-positive breast cancer: Specific correlation with progesterone receptor. Cancer Res 62(17): 4849-4853, 2002.

26 Vinayagam R, Sibson DR, Holcombe C, Aachi V and Davies MP: Association of oestrogen receptor beta 2 (ER beta 2/ER beta $\mathrm{CX}$ ) with outcome of adjuvant endocrine treatment for primary breast cancer-a retrospective study. BMC Cancer 7: 131, 2007.

27 Zhao C, Matthews J, Tujague M, Wan J, Strom A, Toresson G, Lam EW, Cheng G, Gustafsson JA and Dahlman-Wright K: Estrogen receptor beta2 negatively regulates the transactivation of estrogen receptor alpha in human breast cancer cells. Cancer Res 67(8): 3955-3962, 2007.
28 Girault I, Andrieu C, Tozlu S, Spyratos F, Bieche I and Lidereau $\mathrm{R}$ : Altered expression pattern of alternatively spliced estrogen receptor beta transcripts in breast carcinoma. Cancer Lett 215(1): 101-112, 2004.

29 Stygar D, Westlund P, Eriksson H and Sahlin L: Identification of wild type and variants of oestrogen receptors in polymorphonuclear and mononuclear leucocytes. Clin Endocrinol 64(1): 7481, 2006.

30 Hoffmann J, Bohlmann R, Heinrich N, Hofmeister H, Kroll J, Kunzer H, Lichtner RB, Nishino Y, Parczyk K, Sauer G, Gieschen H, Ulbrich HF and Schneider MR: Characterization of new estrogen receptor destabilizing compounds: Effects on estrogen-sensitive and tamoxifen-resistant breast cancer. J Natl Cancer Inst 96(3): 210-218, 2004.

31 Cheng J, Lee EJ, Madison LD and Lazennec G: Expression of estrogen receptor beta in prostate carcinoma cells inhibits invasion and proliferation and triggers apoptosis. FEBS Lett 566(1-3): 169-172, 2004.

32 Pierdominici M, Maselli A, Locatelli SL, Ciarlo L, Careddu G, Patrizio M, Ascione B, Tinari A, Carlo-Stella C, Malorni W, Matarrese $\mathrm{P}$ and Ortona E: Estrogen receptor beta ligation inhibits Hodgkin lymphoma growth by inducing autophagy. Oncotarget 8(5): 8522-8535, 2017.

33 Aghvami M, Pourahmad J, Zarghi A, Eshghi P, Zarei MH, Farzaneh $\mathrm{S}$ and Sattari F: A newly synthetized ferrocenyl derivative selectively induces apoptosis in all lymphocytes through mitochondrial estrogen receptors. Anticancer agents Med Chem 18: 1032, 2018.
Received November 6, 2018

Revised November 26, 2018

Accepted November 27, 2018 